\title{
Testing the white noise hypothesis in high-frequency housing returns of the United States
}

\author{
Aviral Kumar Tiwari ${ }^{1,2} \cdot$ Rangan Gupta $^{3}$ 'Juncal Cunado ${ }^{4}$ Xin Sheng ${ }^{5, *}$ \\ ${ }^{1}$ Rajagiri Business School, Rajagiri Valley Campus, Kochi, India \\ ${ }^{2}$ South Ural State University, Lenin prospect 76, Chelyabinsk, 454080, Russian Federation \\ ${ }^{3}$ Department of Economics, University of Pretoria, Pretoria, South Africa \\ ${ }^{4}$ University of Navarra, School of Economics, Pamplona, Spain \\ ${ }^{5}$ Lord Ashcroft International Business School, Anglia Ruskin University, Chelmsford, UK
}

Received: 9 January 2020

Revised: 29 January 2020

Accepted: 29 January 2020

\begin{abstract}
In the pure time-series sense, weak-form of efficiency of the housing market would imply unpredictability of housing returns. Given this, utilizing a daily dataset of aggregate housing market returns of the United States, we test whether housing market returns are white noise using the blockwise wild bootstrap in a rolling-window framework. We investigate the dynamic evolution of housing market efficiency and find that the white noise hypothesis is accepted in most windows associated with non-crisis periods. However, for some periods before the burst of the housing market bubbles, and during the subprime mortgage crisis, European sovereign debt crisis and the Brexit, the white noise hypothesis is rejected, indicating that the housing market is inefficient in periods of turbulence. Our results have important implications for economic agents.
\end{abstract}

Keywords: blockwise wild bootstrap; randomized block size; serial correlation; weak-form efficiency; white noise test; daily US housing returns

JEL Classification Codes: C12, C58, R31

\section{Introduction}

Historically, housing price returns are considered as a leading indicator for the US economy (Balcilar et al., 2014; Leamer, 2015; Nyakabawo et al., 2015, Emirmahmutoglu et al., 2016), and hence accurate prediction of housing returns is of paramount importance to policy authorities. Given this, if housing returns conform with the weak-form of the efficient market hypothesis $(\mathrm{EMH})$, where the information set consists of past returns, future returns are unpredictable purely based on past price information (Samuelson, 1965; Fama, 1965). Thus, return predictability can be related to the violation of the weak-form of efficiency in the housing market (Case and Shiller, 1989, 1990; Guntermann and Norrbin, 1991).

\footnotetext{
* Corresponding author. E-mail: xin.sheng@anglia.ac.uk.

Citation: Tiwari, A. K, Gupta, R., Cunado, J., and Sheng, X. (2020) Testing the white noise hypothesis in highfrequency housing returns of the United States, Economics and Business Letters, 9(3), 178-188.
}

DOI: 10.17811/ebl.9.3.2020.178-188 
Against this backdrop, we test for the weak-form of EMH, using a unique database that comprises of daily housing returns of the US market (as constructed by Bollerslev et al., (2016)). If indeed housing returns are predictable at the highest possible (daily) frequency, one can predict the future path of low-frequency variables (such as output, unemployment etc.,) measuring economic activity of the US economy also at daily frequency based on models of nowcasting (Bańbura et al., 2011). Naturally, this information should be of tremendous value to not only policymakers but also other economic agents (investors and academicians).

The widely-used tests of financial (equity, bond and currency) markets efficiency, ${ }^{1}$ for example, the variance ratio test (Lo and MacKinlay, 1988), (generalized) spectral test (Hong, 1999; Escanciano and Valasco, 2006), non-parametric sign/rank test (Wright, 2000), and robust automatic portmanteau test (Escanciano and Lobato, 2009), are predominantly based on the assumption of serial independence or martingale difference, and hence, rule out weak dependence that may exist in housing returns. Given this, as far as the econometric framework is concerned, we perform the white noise test of Hill and Motegi (2019) using the blockwise wild bootstrap in a rolling window environment. This test is a promising alternative to the conventional methods, which allows us to control for conditional heteroskedasticity and a broad class of dependence in the housing return series. Moreover, in view of the adaptive market hypothesis (AMH) of Lo $(2004,2005),{ }^{2}$ we perform a rolling window analysis in order to investigate the dynamic evolution of housing market efficiency. It is especially of interest to study how market efficiency is affected during periods of turbulence.

To the best of our knowledge, this is the first attempt to test for the white noise hypothesis and examine the time-varying nature of housing market efficiency using high-frequency (daily) returns of the US. We use a recently developed (general) white noise test of Hill and Motegi (2019) to evaluate the weak-form of EMH for the US housing market across rolling windows. The existing studies in the field (see for example, Gupta and Miller (2012a, b), Canarella et al., (2012, forthcoming), and Herath and Maier (2015)) have relied on low-frequency (monthly, quarterly, or annual) data, and have used unit root tests and long-memory models (with and without structural breaks). In general, these papers conclude that housing price in the US is nonstationary, i.e., weakly-efficient. The remainder of the paper is organized as follows: Section 2 presents the basics of the white noise test, while Section 3 discusses the data and empirical results, with Section 4 concluding the paper.

\section{Methodology: White noise test}

Let $p_{t}$ be the house price index at day $t \in\{1,2, \ldots, n\}$, with $r_{t}=\ln \left(p_{t} / p_{t-1}\right)$ being the logreturns. Let us define the population mean: $\mu=\mathrm{E}\left[r_{t}\right]$, variance $\gamma(0)=\mathrm{E}\left[\left(r_{t}-\mu\right)^{2}\right]$, autocovariance $\gamma(h)=\mathrm{E}\left[\left(r_{t}-\mu\right)\left(r_{t-h}-\mu\right)\right]$, and autocorrelation $\rho(h)=\gamma(h) / \gamma(0)$ for $h \geq$ 1. Our objective is to test the white noise hypothesis of the log-returns, i.e., $r_{t}$, which implies: $H_{0}: \rho(h)=0$ for all $h \geq 1$ against $H_{1}: \rho(h) \neq 0$ for some $h \geq 1$. A rejection of $H_{0}$ is evidence against the weak-form efficiency of the housing market.

We further define the sample mean: $\hat{\mu}_{n}=(1 / n) \sum_{t=1}^{n} r_{t}$, variance $\hat{\gamma}_{n}(0)=(1 / n) \sum_{t=1}^{n}\left(r_{t}-\right.$ $\left.\hat{\mu}_{n}\right)^{2}$, autocovariance $\hat{\gamma}_{n}(h)=(1 / n) \sum_{t=h+1}^{n}\left(r_{t}-\hat{\mu}_{n}\right)\left(r_{t-h}-\hat{\mu}_{n}\right)$, and autocorrelation $\hat{\rho}_{n}(h)=\hat{\gamma}_{n}(h) / \hat{\gamma}_{n}(h)$ for $h \geq 1$. As in Hill and Motegi (2019), we use the Cramér-von Mises $[\mathrm{CvM}]$ statistic, which is based on the sample spectral density:

$$
C_{n}=n \int_{0}^{x}\left\{\sum_{h=1}^{n-1} \hat{\gamma}_{n}(h) \psi_{h}(\lambda)\right\}^{2} d \lambda, \text { where } \psi_{h}(\lambda)=(h \pi)^{-1} \sin (h \lambda) .
$$

\footnotetext{
${ }^{1}$ See Panagiotidis (2005), Aye et al., (2017, 2018), and Gupta and Plakandaras (2019) for detailed literature reviews on efficiency of various financial markets.

${ }^{2}$ The AMH suggests that the degree of return predictability varies as market conditions change, and the level of market efficiency varies over time.
} 
By construction, all $n-1$ possible lags are used, and asymptotically $\gamma(h)$ is estimated for every integer $h \geq 1$. Thus, the $\mathrm{CvM}$ statistic can be used as a formal test of white noise. The test statistic has a non-standard limit distribution under $H_{0}$, and hence, we use the blockwise wild bootstrap approach of Shao (2011) to perform the CvM test, details of which can be found in Hill and Motegi (2019).

\section{Data and results}

We use daily log-returns data based on a new dataset of daily house price series constructed by Bollerslev et al., (2016) using the repeat sales method and comprehensive housing transaction data from DataQuick. The daily Composite 10 Housing Price Index series is based on the weighted average of the house price indices of 10 major Metropolitan Statistical Areas (MSAs) of the US. The 10 MSAs and the specific values of the weights are: Boston (0.212), Chicago (0.074), Denver (0.089), Las Vegas (0.037), Los Angeles (0.050), Miami (0.015), New York (0.055), San Diego (0.118), San Francisco (0.272), and Washington D.C. (0.078), representing the total aggregate value of the housing stock in the 10 MSAs in the year $2000 .{ }^{3}$ Based on data availability, we cover the period from $5^{\text {th }}$ June 2001 to $11^{\text {th }}$ October 2012 , i.e., a total of 2806 observations. The data for the housing returns have been summarized in Table A1 and plotted in Figure A1 in the Appendix of this paper. The data is found to be non-normal, as shown by the overwhelming rejection of the null of normality based on the Jarque-Bera test, due to negative skewness and excess kurtosis. More importantly as also shown in Table A1, the LjungBox test (Ljung and Box, 1978), the Bartel's test (Bartel, 1982), the runs test (Wald and Wolfowtiz, 1940), and the BDS test (Brock et al., 1996), all overwhelmingly reject the null of independence of housing returns. This provides the motivation to use the white noise test of Hill and Motegi (2019) in this paper, which is based on the assumption of (weak) serial dependence.

We now perform the CvM white noise test based on a rolling window approach. ${ }^{4}$ In Figures 1(a) and 1(b) we plot the bootstrapped $p$-values with window size $n \in\{240,480\}$, corresponding to approximately one and two-years, respectively. We use Shao's (2011) blockwise wild bootstrap with block size $b_{n}=\left[c \times(n)^{1 / 2}\right]$. We draw $c \sim U(0.5,1.5)$ independently across 5000 bootstrap samples and rolling windows. The shaded areas in the figures depict the nominal size $p=0.05$. As can be seen from Figure 1(a) under the rolling window-size of 240 observations, the housing market is generally found to be weakly efficient (i.e., the null hypothesis of white noise is rejected), barring the periods between 2004 and 2005, mid-2005, mid-2007 to mid2009, and briefly around mid-2011. Barring the initial two periods over which inefficiency is detected, the latter periods tend to correspond to the global financial crisis (originating from the subprime mortgage crisis) and the European sovereign debt crisis. The inefficiency during 2004 and 2005 is possibly an indication that the housing market was still tied with fundamentals, before getting heated-up and detached to result in the housing market bubble that ultimately collapsed in 2007. When we look at Figure 1(b), which corresponds to the longer window-size of 480 data points, we do tend to obtain similar results compared to those under the smaller window size. However now, the inefficiency during the global financial crisis is prolonged, starting around 2006 and continuing intermittently till mid-2009. The exception in this case is that now we do not see the evidence of inefficiency around mid-2011.

\footnotetext{
${ }^{3}$ The data is downloadable from: http://qed.econ.queensu.ca/jae/datasets/bollerslev001/.

${ }^{4}$ We also conducted the variance ratio, rank, generalized spectral, and robust automatic portmanteau tests referred to in the introduction. Interestingly, barring at longer lags of the generalized spectral and robust automatic portmanteau tests, we obtained evidence against efficiency. However, these tests were conducted for the fullsample, and more importantly, is also based on the assumption of serial independence, which as we have shown does not hold in our dataset, and hence makes these results not completely reliable. Further details of these tests are available upon request from the authors.
} 
Figure 1(a). p-values of CvM Test on Log-Returns of the Composite 10 Housing Price Index with Window Size $n=240$ (Randomized Block Size).

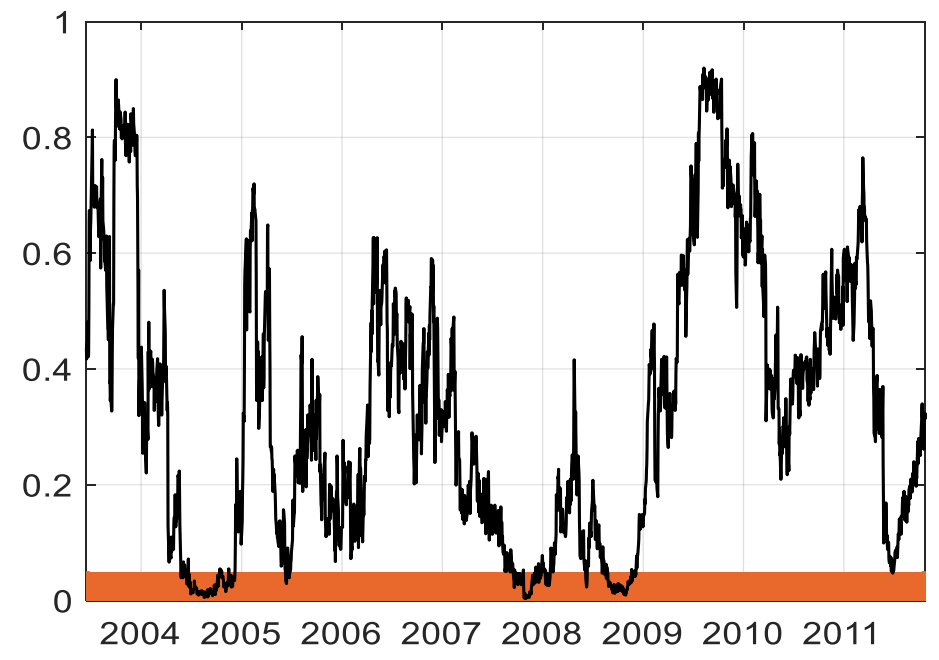

Figure 1(b). p-values of CvM Test on Log-Returns of the Composite 10 Housing Price Index with Window Size $n=480$ (Randomized Block Size).

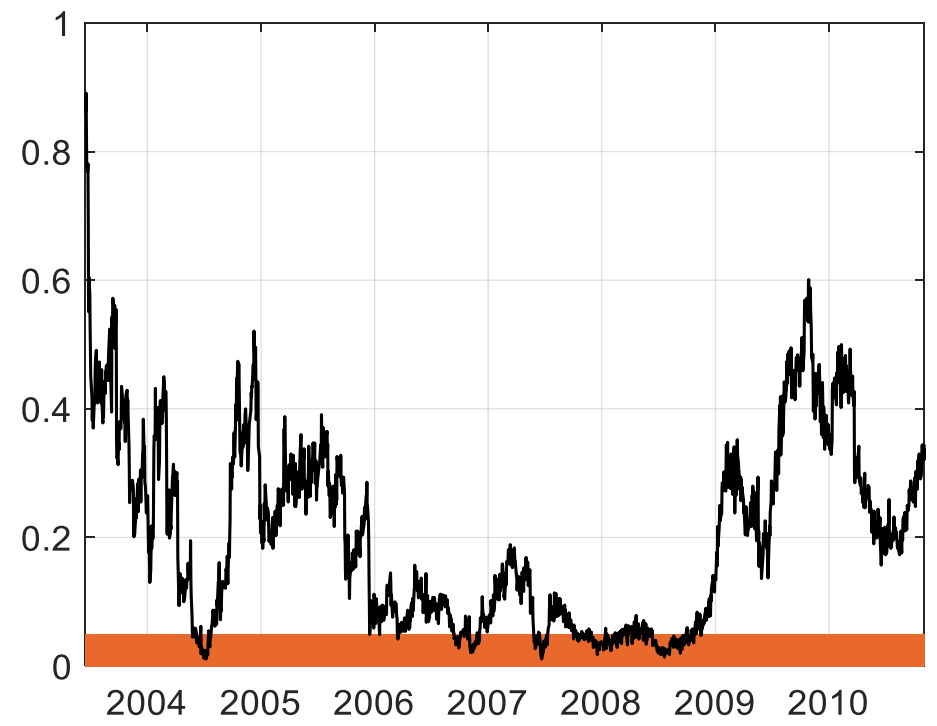

A common perception in the literature on market efficiency is that financial crises result in investor panic and thus lowers the degree of market efficiency (see for example, Lim et al., (2008), Lim and Brooks (2011), and Anagnostidis et al., (2016)). Our results seem to corroborate this line of reasoning based on high-frequency housing market data, and are in line with similar findings associated with bonds, equities, currency, and more recently cryptocurrency markets (Charfeddine et al., 2018; Khuntia and Pattanayak, 2018; Hill and Motegi, 2019; Plakandaras et al., 2019; Tiwari et al., 2019).

\subsection{Additional analyses}

Given that our daily measure of housing returns is a bit outdated, even though it does cover the housing market turmoil of 2007-2008, we also conducted our analysis based on the log-returns computed from the CME-S\&P/Case-Shiller House Price Index (HPI) Continuous Futures (CSCME) derived from the Datastream database of Thomson Reuters. In this case, our sample ranges from 2nd August 2007 to 29th August 2018. We report the results from the white noise test for this data set in Figures 2(a) and 2(b). As can be seen in this case, the evidence against 
Figure 2(a). p-values of CvM Test on Log-Returns of the CME-S\&P/Case-Shiller HPI Continuous Futures (CS-CME) with Window Size $n=240$ (Randomized Block Size).

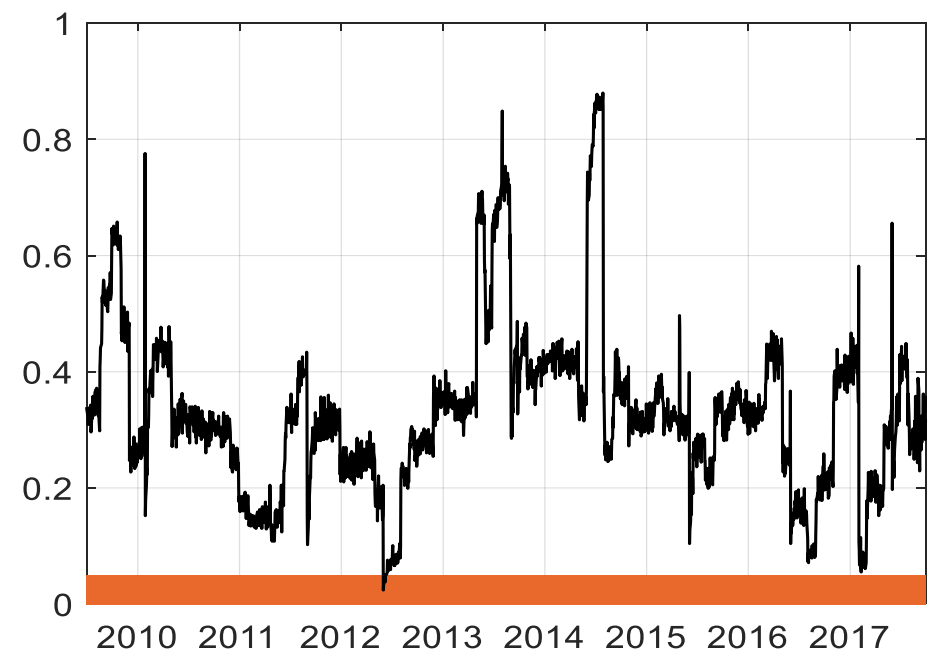

Figure 2(b). p-values of CvM Test on Log-Returns of the CME-S\&P/Case-Shiller HPI Continuous Futures (CS-CME) with Window Size $n=480$ (Randomized Block Size).

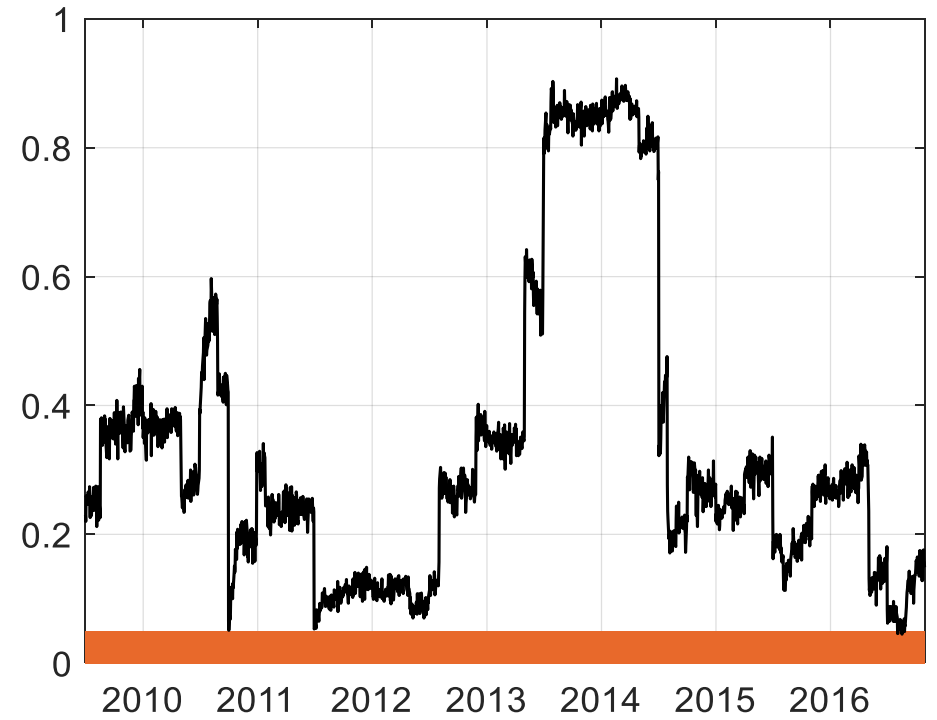

housing market efficiency is weak, with some episodes of inefficiency observed around mid2012 (under the 240 days rolling-window), and towards mid-2016 (under the 240 days rollingwindow). These two periods seem to coincide with the peak of the European sovereign debt crisis and the Brexit, as well as the start of the US-China trade war. These results, as above, once again highlights the point that inefficiency is likely to creep into the housing during periods of crises. ${ }^{5}$

\footnotetext{
${ }^{5}$ Based on the suggestion of an anonymous referee, we also conducted the white noise test on log-returns of the S\&P 500 index and 10-year government bond index, with the data derived from Datastream, covering the same sample period (2nd August 2007 to 29th August 2018) as the CME-S\&P/Case-Shiller House Price Index (HPI) Continuous Futures (CS-CME). These results have been reported in Figures A2 and A3 in the Appendix of the paper. As can be seen, inefficiency is observed in both markets in the wake of the Brexit, and the US-China trade war post-2016. Further, additional evidence of bond market predictability is observed, not surprisingly, during the European sovereign debt crisis, and also in 2015, possibly due to heightened probability of bankruptcy in Greece, and declining oil prices, which was interpreted as a sign of a marked slowdown in the global economy, and thus agents wanting to invest in safe-havens.
} 
Figure 3(a). p-values of CvM Test on Log-Returns of the S\&P Real Estate Investment Trusts (REITs) Index with Window Size $n=240$ (Randomized Block Size).

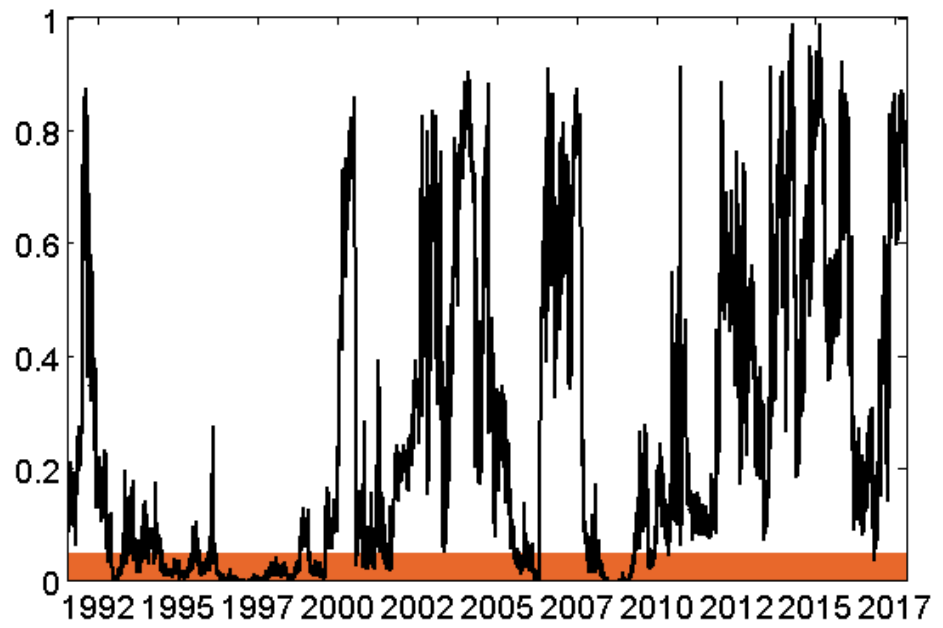

Figure 3(b). p-values of CvM Test on Log-Returns of the S\&P Real Estate Investment Trusts (REITs) Index with Window Size $n=480$ (Randomized Block Size).

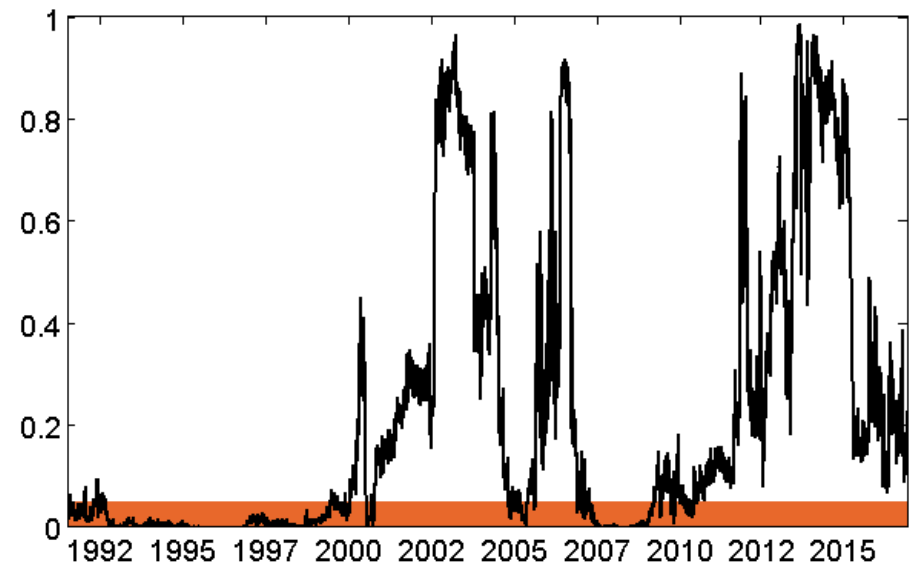

Further, given that data on (S\&P) Real Estate Investment Trusts (REITs) index is available at daily frequency for the US economy from Datastream, dating back to 1989, we reconducted the white noise test on REITs log-returns over the period of $1^{\text {st }}$ August 1989 till $13^{\text {th }}$ September, 2018 (based on data availability). These results have been reported in Figures 3(a) and 3(b). As can be seen, when compared to Figures 1 and 2, the results from the REITs index are similar to those derived over the common period involving the returns of the two housing price indices. However, at the beginning of the sample period, i.e., the decade of the 1990s, the REITs market was primarily inefficient, probably due to its still nascent nature. ${ }^{6}$

\section{Conclusion}

We test for the weak-form of EMH in daily housing returns of the US based on the white noise test of Hill and Motegi (2019), which relaxes the assumption of serial independence and the martingale difference sequence. This, in turn, allows us to control for conditional heteroskedasticity, and higher level forms of dependence in the housing return series. Further, in line with the adaptive market hypothesis (AMH), we run a rolling-window analysis to capture

\footnotetext{
${ }^{6}$ Time-varying evidence of inefficiency in REITs market was also detected by Bampinas et al., (2016).
} 
time-varying market efficiency. We find that the white noise hypothesis is accepted in most windows associated with non-crisis periods. However, for some periods before the burst of the housing market bubbles, and during the subprime mortgage crisis, European sovereign debt crisis and the Brexit, the white noise hypothesis is rejected, indicating that the US housing market is inefficient during periods of turbulence.

Our results should be of tremendous value to policymakers, as they can conduct highfrequency predictability of possible recessions based on lagged values of daily housing returns, especially during periods of crises. In addition, the rejection of the white noise hypothesis, since it indicates the presence of non-zero autocorrelation at some lags, can serve as a helpful signal of arbitrage opportunities for investors in the housing market. Finally, from the perspective of an academician, we can conclude that the housing market of the US at a high-frequency is characterized by the $\mathrm{AMH}$, and hence we would require regime-dependent frameworks to model housing market returns appropriately.

It must be realized that, while the US has high-frequency housing market data, this is not likely to be the case for other economies, and hence our analysis cannot necessarily be extended to provide cross-country evidence. However, we can always extend our analysis by conducting the white noise test on REITs of other advanced and emerging market economies.

\section{Acknowledgements}

We would like to thank the Editor, Professor Theodore Panagiotidis, and two anonymous referee for many helpful comments. However, any remaining errors are solely ours.

\section{References}

Anagnostidis, P., Varsakelis, C., and Emmanouilides, C. J. (2016) Has the 2008 Financial Crisis Affected Stock Market Efficiency? The Case of Eurozone, Physica A: Statistical Mechanics and its Applications, 447, 116-128.

Aye, G. C., Chang, T., Chen, W. Y., Gupta, R., and Wohar, M. E. (2018) Testing the Efficiency of the Art Market Using Quantile-Based Unit Root Tests with Sharp and Smooth Breaks, The Manchester School, 86(4), 488-511.

Aye, G. C., Gil-Alana, L. A., and Gupta, R., and Wohar, M. E. (2017) The efficiency of the art market: Evidence from variance ratio tests, linear and nonlinear fractional integration approaches, International Review of Economics \& Finance, 51(C), 283-294.

Balcilar, M., Gupta, R., and Miller, S. M. (2014) Housing and the Great Depression, Applied Economics, 46(24), 2966-2981.

Bańbura, M., Giannone, D., and Reichlin, L. (2011) Nowcasting, in M.P. Clements \& D.F. Hendry (Eds.), The Oxford Handbook of Economic Forecasting, 193-224, Oxford: Oxford University Press, United Kingdom.

Bampinas, G., Fountas, S., and Panagiotidis, T. (2016) The day-of-the-week effect is weak: Evidence from the European real estate sector, Journal of Economics and Finance, 40(3), 549-567.

Bartels, R. (1982) The rank version of von Neumann's ratio test for randomness, Journal of American Statistical Association, 77, 40-46.

Bollerslev, T., Patton, A., and Wang, W. (2016) Daily house price index: construction modelling and longer-run predictions, Journal of Applied Econometrics, 31, 1005-1025.

Brock, W. A., Dechert, W. D., Schieinkman, J. A., and LeBaron, B. (1996) A test for independence based on the correlation dimension, Econometric Reviews, 15, 197-235.

Canarella, G., Miller, S., and Pollard, S. (2012) Unit roots and structural change: An application to US housing price indices, Urban Studies, 49, 757-776. 
Canarella, G., Gil-Alana, L. A., Gupta, R., and Miller, S. M. (2020) Persistence and Cyclical Dynamics of U.S. and U.K. House Prices: Evidence from Over 150 Years of Data, Urban Studies, in press.

Case, K. E., and Shiller, R. J. (1989) The Efficiency of the Market for Single Family Homes, American Economic Review, 79, 125-137.

Case, K. E., and Shiller, R. J. (1990) Forecasting Prices and Excess Returns in the Housing Market, Journal of the American Real Estate and Urban Economics Association, 18, 253 273.

Charfeddine, L., Khediri, K. B., Aye, G. C., and Gupta, R. (2018) Time-varying efficiency of developed and emerging bond markets: Evidence from long-spans of historical data, Physica A: Statistical Mechanics and its Applications, 505(C), 632-647.

Emirmahmutoglu, F., Balcilar, M., Apergis, N., Simo-Kengne, B. D., Chang, T., and Gupta, R. (2016) Causal Relationship between Asset Prices and Output in the US: Evidence from State-Level Panel Granger Causality Test, Regional Studies, 50(10), 1728-1741.

Escanciano, J. C., and Lobato, I. N. (2009) An Automatic Portmanteau Test for Serial Correlation, Journal of Econometrics, 151, 140-149.

Escanciano, J. C., and Velasco, C. (2006) Generalized Spectral Tests for the Martingale Difference Hypothesis, Journal of Econometrics, 134, 151-185.

Fama, E. (1965) The behaviour of stock market prices, Journal of Business, 38, 34-105.

Guntermann, K. L., and Norrbin, S. C. (1991) Empirical Tests of Real Estate Market Efficiency, Journal of Real Estate Finance and Economics, 4, 297-313.

Gupta, R., and Miller, S. M. (2012a) "Ripple effects" and forecasting home prices in Los Angeles, Las Vegas, and Phoenix, The Annals of Regional Science, 48(3), 763-782.

Gupta, R., and Miller, S. M. (2012b) The Time-Series Properties of House Prices: A Case Study of the Southern California Market, The Journal of Real Estate Finance and Economics, 44(3), 339-361.

Gupta, R., and Plakandaras, V. (2019) Efficiency in BRICS Currency Markets Using LongSpans of Data: Evidence from Model-Free Tests of Directional Predictability, Journal of Economics and Behavioral Studies, 11(1), 152-165.

Herath, S., and Maier (2015) Informational efficiency of the real estate market: A metaanalysis, Journal of Economic Research, 20, 117-168.

Hill, J. B., and Motegi, K. (2019) Testing the white noise hypothesis of stock returns, Economic Modelling, 76, 231-242.

Hong, Y. (1999) Hypothesis testing in time series via the empirical characteristic function: a generalized spectral density approach, Journal of the American Statistical Association, 94, 1201-1220.

Khuntia, S., and Pattanayak, J.K. (2018) Adaptive market hypothesis and evolving predictability of bitcoin, Economics Letters, 167, 26-28.

Leamer, E. E. (2015) Housing really is the business cycle: What survives the lessons of 200809?, Journal of Money, Credit and Banking, 47(S1), 43-50.

Lim, K. P., Brooks, R. D., and Kim, J. H. (2008) Financial Crisis and Stock Market Efficiency: Empirical Evidence from Asian Countries, International Review of Financial Analysis, 17, 571-591.

Lim, K. P., and Brooks, R. (2011) The evolution of stock market efficiency over time: A survey of the empirical literature, Journal of Economic Surveys, 25(1), 69-108.

Ljung, G. M., and Box, G. E. P. (1978) On a measure of the lack of fit in time series models, Biometrika, 65, 297-303.

Lo, A. W. (2004) The adaptive markets hypothesis: market efficiency from an evolutionary perspective, Journal of Portfolio Management, 30, 15-29. 
Lo, A. W. (2005) Reconciling efficient markets with behavioral finance: the adaptive markets hypothesis, Journal of Investment Consulting, 7, 21-44.

Lo, A. W., and MacKinlay, A. C. (1988) Stock Market Prices Do Not Follow Random Walks: Evidence from a Simple Specification Test, Review of Financial Studies, 1, 41-66.

Nyakabawo, W. V., Miller, S. M., Balcilar, M., Das, S. and Gupta, R. (2015) Temporal Causality between House Prices and Output in the U.S.: A Bootstrap Rolling-window Approach, North American Journal of Economics and Finance, 33(1), 55-73.

Panagiotidis, T. (2005) Market capitalization and efficiency. Does it matter? Evidence from the Athens Stock Exchange, Applied Financial Economics, 15(10), 707-713.

Plakandaras, V., Gupta, R., Gil-Alana, L. A., and Wohar, M. E. (2019) Are BRICS exchange rates chaotic?, Applied Economics Letters, 26(13), 1104-1110.

Samuelson P. A. (1965) Proof that properly anticipated prices fluctuate randomly, Industrial Management Review, 6, 41-9.

Shao, X. (2011) A bootstrap-assisted spectral test of white noise under unknown dependence, Journal of Econometrics, 162(2), 213-224.

Tiwari, A. K., Aye, G. C., and Gupta, R. (2019) Stock market efficiency analysis using long spans of Data: A multifractal detrended fluctuation approach, Finance Research Letters, 28, 398-411.

Wald, A., and Wolfowtiz, J. (1940) On a test whether two samples are form the same population, Annals of Mathematical Statistics, 11, 147-162.

Wright, J. H. (2000) Alternative Variance-Ratio Tests Using Ranks and Signs, Journal of Business and Economic Statistics, 18, 1-9.

\section{Appendix A - Additional tables and figures}

Table A1. Summary Statistics.

\begin{tabular}{lr}
\hline \hline Statistic & Log-Returns of Composite 10 Housing Price Index \\
\hline Mean & 0.0001 \\
Median & 0.0002 \\
Maximum & 0.0066 \\
Minimum & -0.0063 \\
Std. Dev. & 0.0016 \\
Skewness & -0.2109 \\
Kurtosis & 3.7697 \\
Jarque-Bera & $90.0643^{*}$ \\
Observations & 2806 \\
Ljung-Box $(p=36)$ & $1584.0000^{*}$ \\
Runs Test & $250.7000^{*}$ \\
Bartel's Test & $-3.9160^{*}$ \\
\hline & \\
\hline$m=2$ & $4.5600^{*}$ \\
$m=3$ & $6.4954^{*}$ \\
$m=4$ & $8.1053^{*}$ \\
$m=5$ & $9.5640^{*}$ \\
$m=6$ & BDS Test \\
\hline \hline
\end{tabular}

Note: ${ }^{*}$ indicates significance at $1 \%$ level; $m$ stands for the dimension of the BDS test. 
Figure A1. Log-Returns of Composite 10 Housing Price Index.

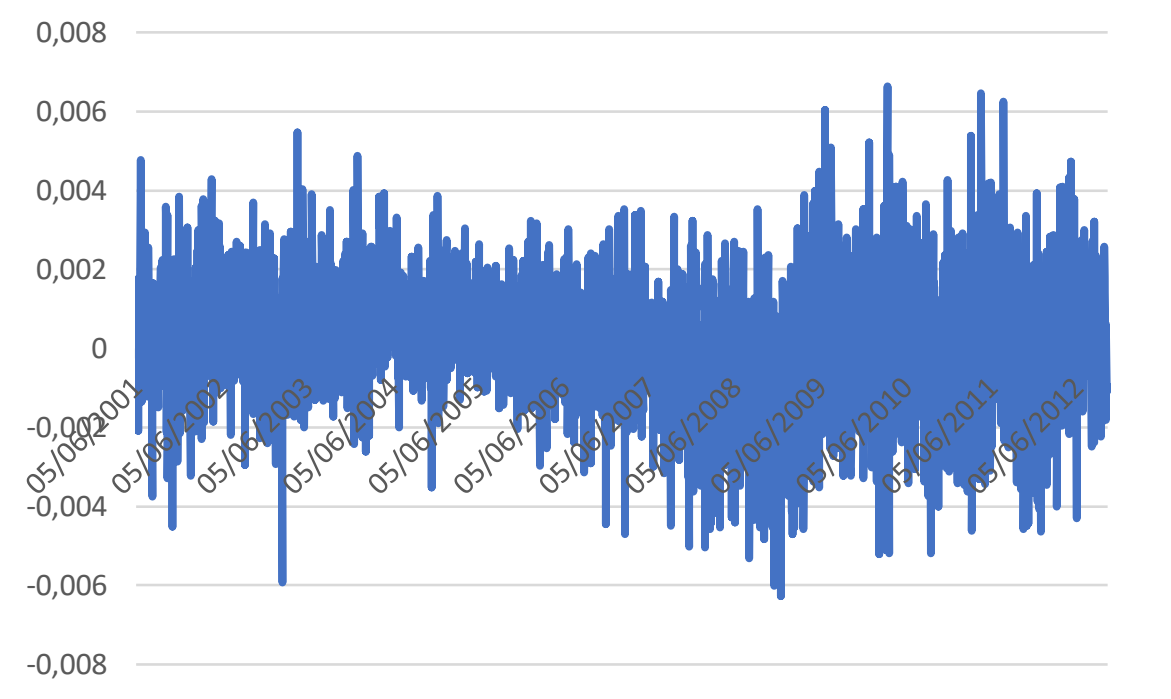

Figure A2(a). p-values of CvM Test on Log-Returns of the S\&P 500 Index with Window Size $n=240$ (Randomized Block Size).

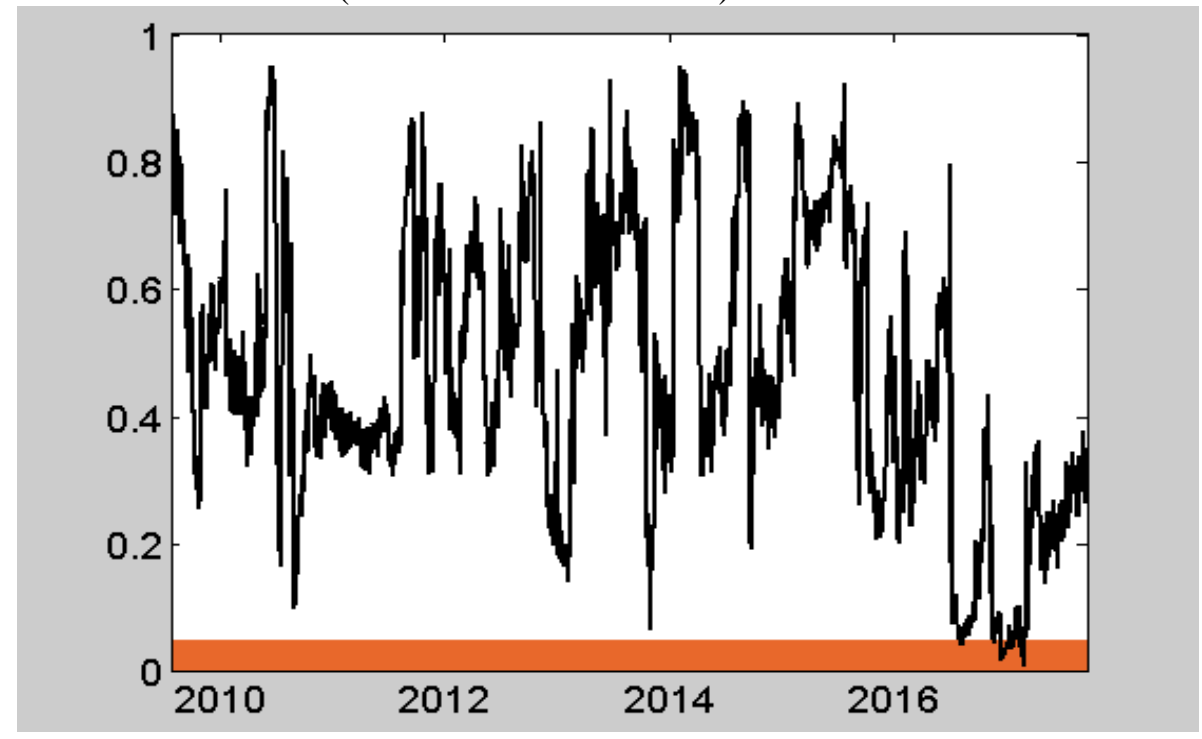

Figure A2(b). p-values of CvM Test on Log-Returns of the S\&P 500 Index with Window Size $n=480$ (Randomized Block Size).

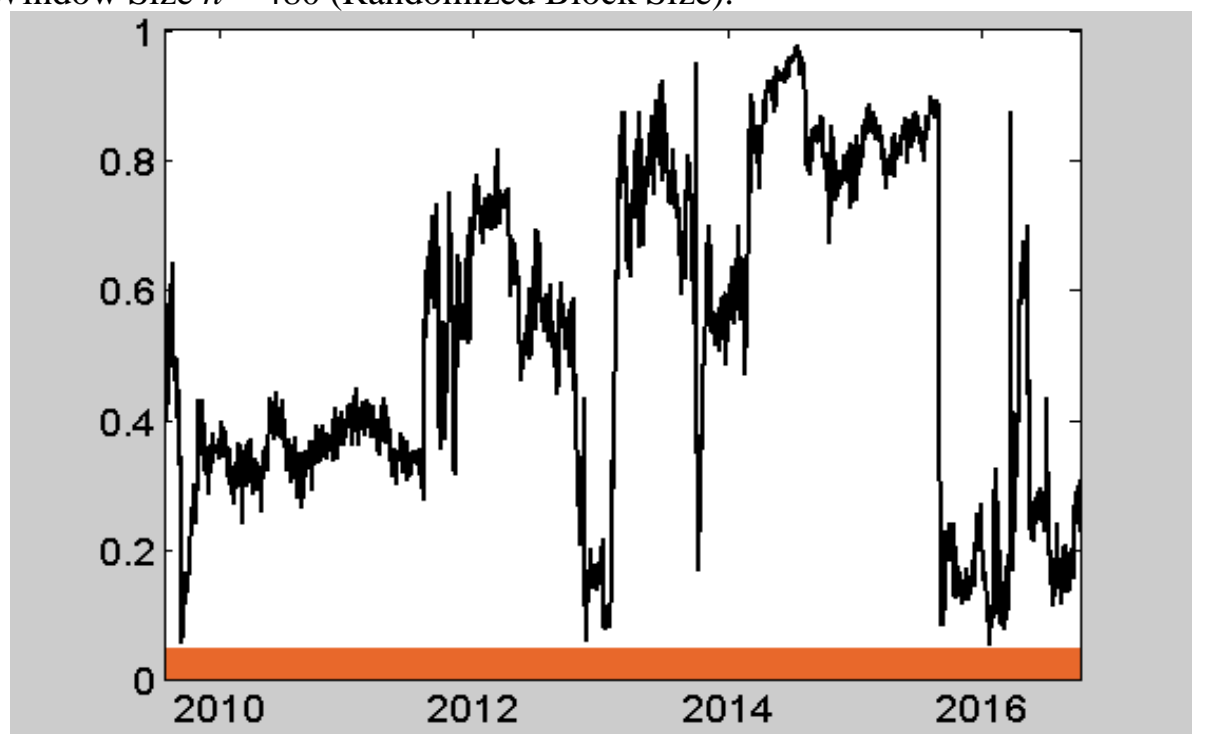


Figure A3(a). p-values of CvM Test on Log-Returns of the 10-Year Government Bond Index with Window Size $n=240$ (Randomized Block Size).

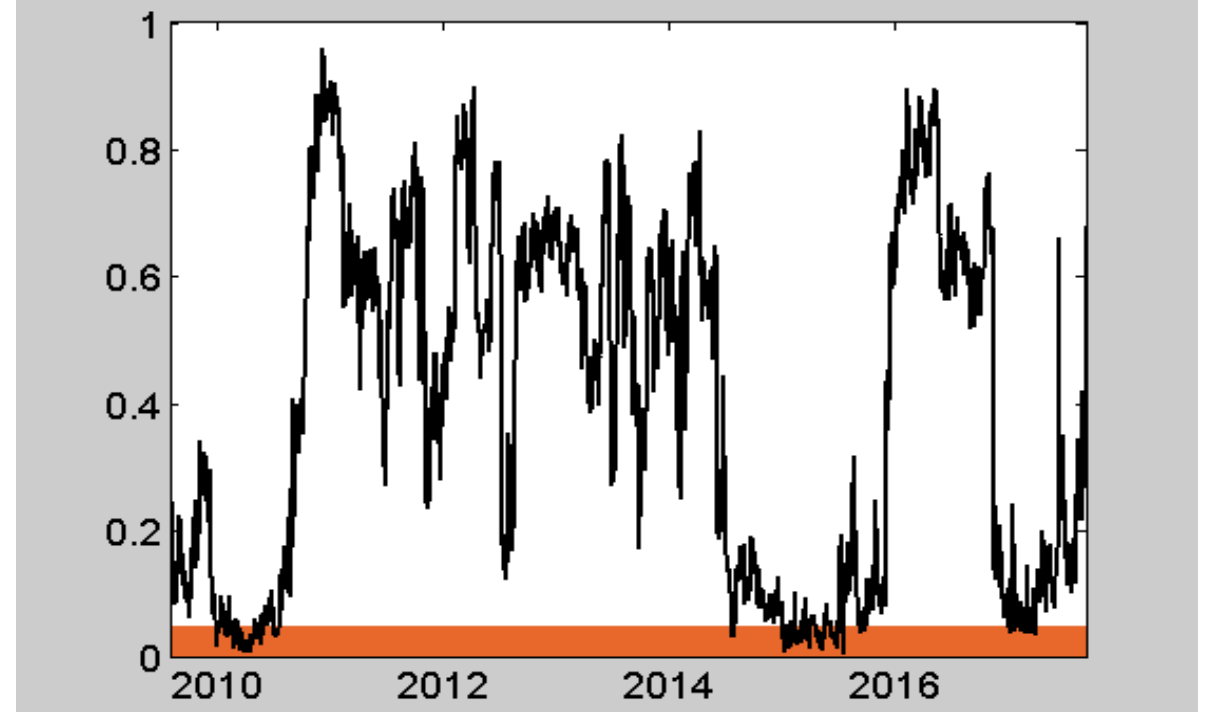

Figure A3(b). p-values of CvM Test on Log-Returns of the 10-Year Government Bond Index with Window Size $n=480$ (Randomized Block Size).

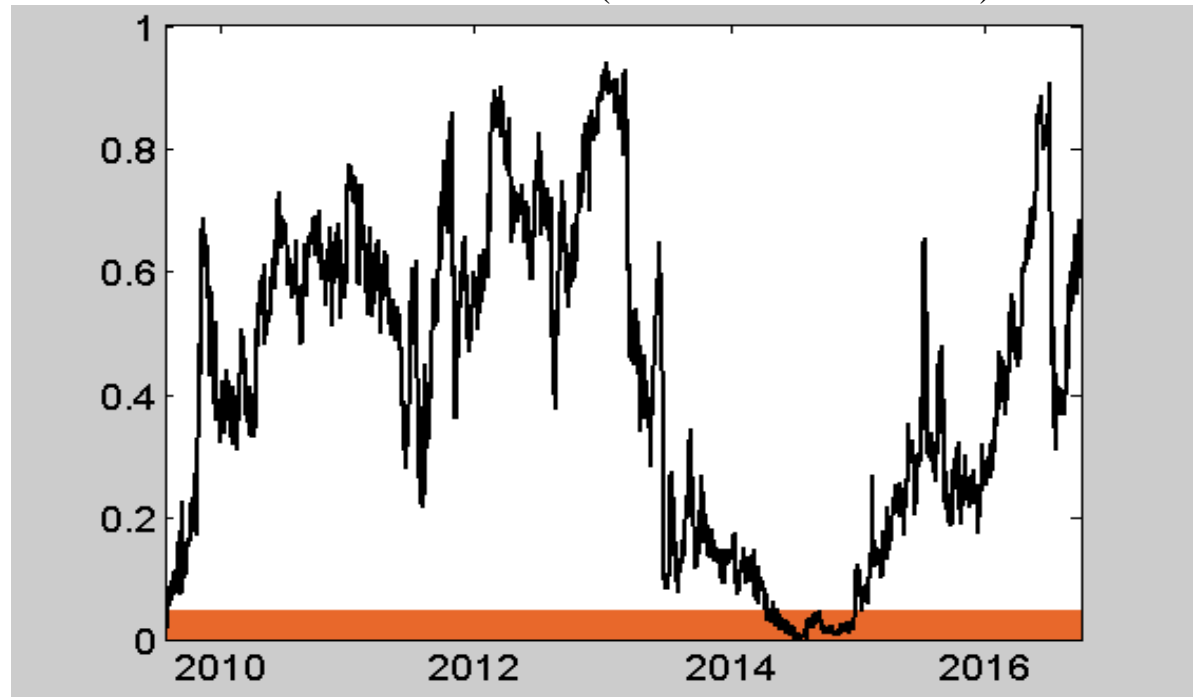

